\title{
Study on Antiseismic Effect of Different Thicknesses of Shock Absorption Layer on Urban Shallow Buried Double Arch Rectangular Tunnel
}

\author{
Jian Wang, 1 Yulong Hu, ${ }^{1}$ Baiyong Fu, ${ }^{2}$ Hongwei Shan, ${ }^{3}$ Hanghang Wei $\mathbb{D}^{4}$ \\ and Guangyao Cui $\mathbb{1}^{4}$ \\ ${ }^{1}$ ShangHai Municipal Engineering Design Institute (Group) Co.,Ltd., Shanghai 200000, China \\ ${ }^{2}$ CCCC Highway Bridges Nationals Engineering Research Centre CO., Ltd.,, Beijing 100120, China \\ ${ }^{3}$ CCCC-SHEC Sixth Engineering Co.,Ltd.,, Xi'an 710000, Shaanxi, China \\ ${ }^{4}$ School of Civil Engineering, North China University of Technology, Beijing 100144, China
}

Correspondence should be addressed to Hanghang Wei; weihang1403608805@163.com

Received 3 December 2021; Accepted 6 January 2022; Published 28 January 2022

Academic Editor: Honglue Qu

Copyright (๑ 2022 Jian Wang et al. This is an open access article distributed under the Creative Commons Attribution License, which permits unrestricted use, distribution, and reproduction in any medium, provided the original work is properly cited.

With the development of urban tunnels, more and more studies focus on the antiseismic design of tunnels. Setting up a shock absorption layer is a very effective means in the earthquake resistance of an urban tunnel. In this paper, in order to study the influence of the thickness of a shock absorption layer on the antiseismic effect of the urban shallow buried double arch rectangular tunnel, the Tengzhou-Fenghuang tunnel is used as the research background. Firstly, the model is established by finite element software to analyze the tunnel with $50 \mathrm{~mm}, 100 \mathrm{~mm}$, and $150 \mathrm{~mm}$ thick shock absorption layers, and analyze the tunnel displacement, stress, and safety factors of different models under the action of a seismic wave. Finally, the calculation results are compared and analyzed with those of the model without the shock absorption layer to summarize the thickness of the shock absorption layer suitable for urban shallow buried rectangular tunnels. The results show that the displacement and stress of tunnel lining are significantly reduced, and the safety factor is significantly improved after setting the shock absorption layer. Among them, the tunnel with a $100 \mathrm{~mm}$ thick shock absorption layer has the greatest reduction in principal stresses, the greatest increase in safety factor, and the best antiseismic effect, while the construction costs are not high. It is recommended that the urban shallow buried double arch rectangular tunnel be constructed with a $100 \mathrm{~mm}$ thick shock absorption layer.

\section{Introduction}

In recent years, many tunnels have been damaged in the earthquake $[1,2]$; therefore, there are more and more research studies on the antiseismic technology of tunnels. At present, there are three aspects in the research of improving the tunnel antiseismic performance, which are to improve the strength of tunnel surrounding rock, enhance the toughness and strength of tunnel lining, and construct a shock absorption layer. The main way to improve the strength of surrounding rock is to set anchor bolts to grout the surrounding rock of the tunnel so as to improve the strength of surrounding rock. At present, the research on surrounding rock grouting has been relatively perfect, and the main research achievements include exploring the working mechanism of grouting anchor [3], the interaction between anchor bolts and surrounding rock [4], and evaluating the grouting effect of the surrounding rock [5-7]. Adding steel fiber, glass fiber, and other materials in the concrete can greatly improve the mechanical properties of concrete $[8,9]$, and using this composite concrete as a lining material in tunnel construction can effectively improve the antiseismic performance of tunnel lining. What is more, there are many research studies on fiber reinforced concrete. Through shaking table test, it is found that polypropylene fiber concrete as lining can reduce the stress and strain of a tunnel under earthquake action [10]. Steel fiber reinforced concrete has better antiseismic performance than ordinary 
reinforced concrete $[11,12]$. Although there are many research studies on fiber reinforced concrete, the application of fiber reinforced concrete in engineering is less, and its antiseismic effect in specific projects is not clear, so further research is needed.

The shock absorption layer is added between the tunnel lining and the surrounding rock, which can reduce the transmission of adverse effects of surrounding rock to the tunnel lining. Xin et al. [13] thought that setting a shock absorption layer is the most simple and effective means to improve the antiseismic performance of a tunnel. The shock absorption layer can reduce the effect of a seismic wave on lining and reduce the pressure from surrounding rock. Huang et al. [14] carried out an antiseismic test on a circular tunnel with different material shock absorption layers through shaking table test, and the results show that the sponge rubber plate has a good antiseismic effect. In addition, the exploration of new damping materials is also carried out. Jiang and Zhang [15] studied the seismic behavior of foam concrete. The results show that foam concrete can prevent lining from being damaged under an earthquake. Su et al. [16] were the first to apply the closed-cell aluminum foam in designing a shock-absorbing layer for a high-speed railway tunnel and studied the seismic behavior of closed-cell aluminum foam. Shaking table test and numerical simulation are two particularly effective methods to study the antiseismic performance of the shock absorbing layer. Many scholars [17-19] have discovered the antiseismic mechanism and antiseismic performance of the shock-absorbing layer through shaking table test and numerical simulation.

Compared with the horseshoe tunnel and the circular tunnel, the rectangular tunnel has uneven stress distribution. Therefore, the rectangular tunnel has more stringent requirements on the antiseismic technology of the tunnel, and there is a lack of research on the antiseismic technology of the rectangular tunnel at present. In order to explore the influence of the thickness of the shock-absorbing layer on the antiseismic performance of an urban shallow buried double arch rectangular tunnel, based on the Fenghuang tunnel, this paper analyzes the displacement, stress, and safety factor of the tunnel lining with three different thickness shock absorption layers of $50 \mathrm{~mm}, 100 \mathrm{~mm}$, and $150 \mathrm{~mm}$, and combined with the engineering practice, obtains the appropriate antiseismic measures for the urban shallow buried double arch rectangular tunnel.

\section{Tunnel Situation}

Fenghuang tunnel is located in a flat terrain with plain landform. The upper part of the stratum is clay and the lower part is mainly sandstone (rock quality grade is IV) [20]. The seismic fortification intensity in this area is 6 degrees, and the basic design seismic acceleration value is $0.05 \mathrm{~g}$ [21].

The tunnel adopts a closed box structure. There is a layer of $0.2 \mathrm{~m}$ cushion between the bottom of the tunnel and the surrounding rock. The cross section of the tunnel is shown in Figure 1. C40 concrete [22] is used for tunnel lining, and C20 concrete is used for cushion. The span of the tunnel is $26.3 \mathrm{~m}$, and the height is $8.2 \mathrm{~m}$. The thickness of the roof, bottom plate, and the middle wall of the tunnel lining are $0.8 \mathrm{~m}$, $1.1 \mathrm{~m}$, and $0.8 \mathrm{~m}$, respectively.

\section{Software General Situation and Calculation Condition}

3.1. Simulation Method. ABAQUS is a general finite element software, which mainly consists of two analysis modules, ABAQUS/Standard and ABAQUS/Explicit. It can be used to solve linear and nonlinear problems. It is widely used in many scientific research fields and engineering fields such as machinery, water conservancy, materials, and civil engineering. Compared with other software, ABAQUS has several advantages. First, it has powerful functions. This software is a simulation software integrating mechanics, electromagnetism, and thermodynamics, and its operation is very simple. Second, it can solve many kinds of nonlinear problems; in nonlinear analysis, ABAQUS can automatically select corresponding load increments and convergence rates so as to ensure accurate solutions in the analysis process. Third, it has a rich material model library and cell library, which can select different models and elements according to different problems.

At present, many experts have carried out an antiseismic calculation of slope, house, and underground structures by ABAQUS. The antiseismic calculation methods of underground structures mainly include the static method, quasistatic method, and dynamic response analysis method. The error of the static method is large, and now, the main method is the quasistatic method. In the antiseismic calculation of the underground structure, due to the size limitation of the model, it is necessary to transform the semiinfinite boundary into the model with a boundary. The seismic wave will reflect at the boundary of the model, which will interfere with the calculation results. Therefore, appropriate boundary conditions should be set up when the model is established. At present, the commonly used boundary conditions include viscous boundary, viscoelastic boundary, and infinite element boundary. The infinite element boundary can simulate the actual situation of zero displacement of soil at infinity and reduce the calculation amount of the model. Therefore, the infinite element boundary is selected as the boundary condition in this paper.

3.2. Calculation Model. The model is established according to the geological conditions and the tunnel size. When the model is established, the buried depth of the tunnel is $8 \mathrm{~m}$, and the width of the tunnel is $26.3 \mathrm{~m}$. The width of the model is about 10 times of the tunnel, so the width of the model is about $290 \mathrm{~m}$, and the thickness of the model is $20 \mathrm{~m}$. The upper part of the model is silty clay with a thickness of $8 \mathrm{~m}$, the middle part is grade IV surrounding rock with a thickness of $38 \mathrm{~m}$, and the bottom is grade II surrounding rock with a thickness of $20 \mathrm{~m}$. When the model is established, the Mohr Coulomb constitutive model is adopted for surrounding rock, and the linear elastic constitutive model is adopted for the tunnel lining, cushion, and shock absorption layer. In order to make the calculation results accurate and 


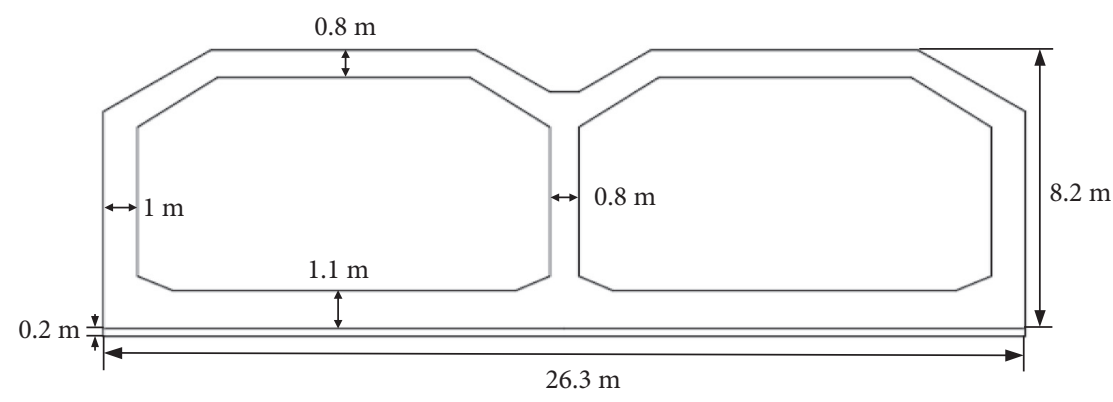

FIgURE 1: Tunnel cross section.

reduce the amount of calculation, the mesh division of tunnel lining is more compact and that of surrounding rock is loose. The boundary condition of the model is that there is no rotation and displacement at the bottom and around, and the infinite element boundary is set at the same time, and the upper boundary is unconstrained. The calculation model is shown in Figure 2.

3.3. Calculation Parameters. The surrounding rock conditions are selected according to geological survey data. The material of the shock absorption layer is rubber plate. The calculation parameters are shown in Table 1.

3.4. Calculation Conditions. This paper studies the influence of the thickness of the shock absorption layer on the antiseismic effect of the urban shallow buried double arch rectangular tunnel. There are four groups of calculation conditions, one of which has no shock absorption layer as the control group, and the other three conditions have the shock absorption layer of different thicknesses. The calculation conditions are shown in Table 2.

3.5. Measurement Arrangement. One monitoring section is set every $5 \mathrm{~m}$ in the tunnel, and a total of 5 monitoring sections are set, which are $S 1 \sim S 5$, respectively; the section distribution is shown in Figure 3. Nine monitoring points are set up for each monitoring section, and the principal stress, shear stress, and safety factor of each measuring point are analyzed. The arrangement of measuring points is shown in Figure 4.

3.6. Load Input. The seismic fortification intensity of the Tengzhou area is 6 degrees, so the acceleration wave of the Wolong station of the Wenchuan earthquake is selected as the seismic wave, which is standardized according to the intensity of 7 degrees. The peak acceleration of the seismic wave is $0.1 \mathrm{~g}$, and the duration is $15 \mathrm{~s}$. The loading mode of this numerical simulation is conventional dynamic loading, and the seismic waves in three directions $(x, y, z)$ are transmitted to the upper part at the same time through the bottom of the model. The acceleration curve is shown in Figure 5.
3.7. Calculation Method of Antiseismic Effect. In order to check the antiseismic performance of the tunnel, it is usually necessary to calculate the safety factor of the lining. The safety factor is calculated according to the specification [23] as follows:

$$
N=\frac{1}{2} E\left(\varepsilon_{1}+\varepsilon_{2}\right) b h
$$

In the above formula, $N$ represents the axial force; $E$ represents the modulus of elasticity; $\varepsilon_{1}$ and $\varepsilon_{2}$ are the internal and external strains of tunnel lining; $h$ represents section thickness; $b$ is the section width, taken as $1 \mathrm{~m}$.

$$
M=\frac{1}{12} E\left(\varepsilon_{1}-\varepsilon_{2}\right) b h^{2} .
$$

In the above formula, $M$ represents the bending moment, and others are the same as formula (1).

$$
\begin{aligned}
& K N \leq \varphi \alpha R_{\mathrm{a}} b h, \\
& K N \leq \varphi \frac{1.75 R l b h}{6 e_{0} / h-1} .
\end{aligned}
$$

In formulas (3) and (4), $K$ represents the safety factor of tunnel lining; $\varphi$ represents the coefficient of longitudinal bending; $\alpha$ represents the influence coefficient of axial eccentricity; $R_{a}$ represents the ultimate compressive strength; $e_{0}$ represents the eccentricity; $R_{l}$ represents the ultimate tensile strength, and the rest is the same as formula (1).

According to the simulation results, the antiseismic effects of displacement, principal stress, and safety factor of different thickness shock absorption layers are calculated. The calculation formula of antiseismic effect is as follows:

$$
\rho=\frac{Q_{b}-Q_{a}}{Q_{a}} .
$$

In the above formula, $\rho$ represents the antiseismic effect of each simulation result; $Q_{a}$ represents the value of maximum convergence of side wall, principal stress, and safety factor without the shock absorption layer (condition 1); $Q_{b}$ represents the value of maximum convergence of side wall, principal stress, and safety factor when setting different thickness shock absorption layer (condition $2 \sim$ condition 4 ). 


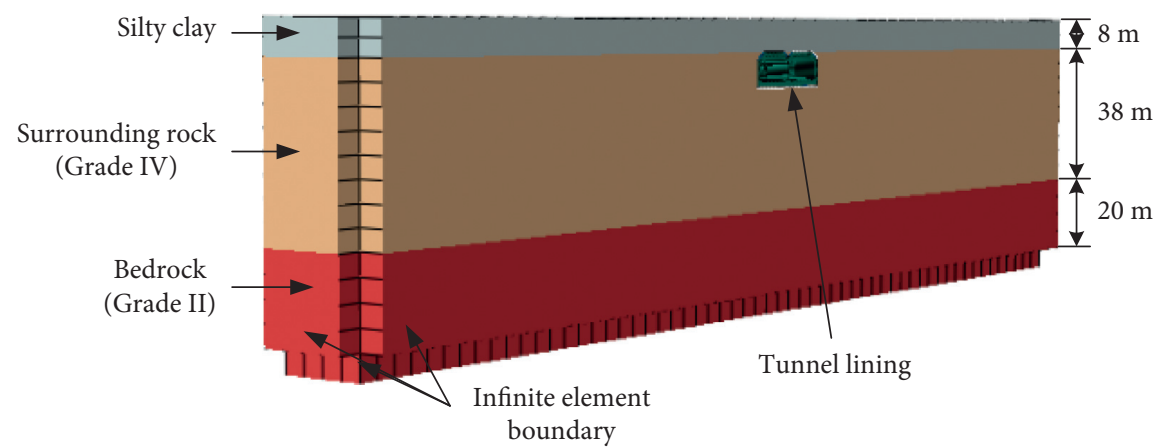

(a)

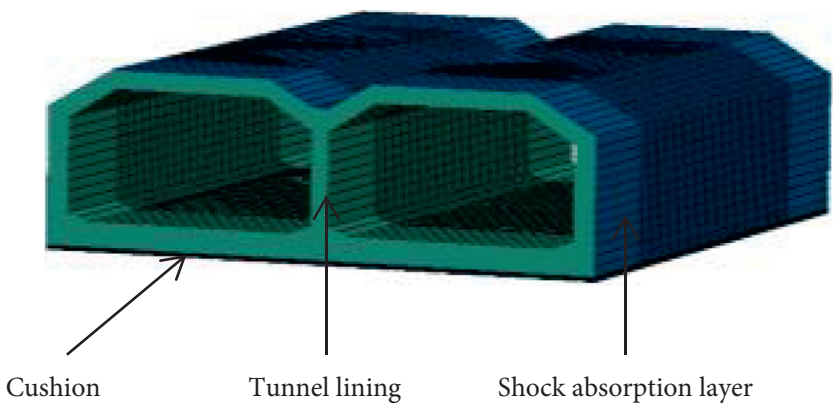

(b)

Figure 2: Calculation model. (a) Overall model. (b) Tunnel lining.

TABLE 1: Calculation parameters.

\begin{tabular}{|c|c|c|c|c|c|}
\hline Material name & Weight $\left(\mathrm{N} / \mathrm{m}^{3}\right)$ & Poisson's ratio & Modulus $(\mathrm{Pa})$ & Friction angle $\left({ }^{\circ}\right)$ & Cohesion $(\mathrm{Pa})$ \\
\hline Surrounding rock & $2.2 \times 10^{4}$ & 0.30 & $5 \times 10^{9}$ & 35.0 & $5 \times 10^{5}$ \\
\hline Bedrock & $2.5 \times 10^{4}$ & 0.20 & $2 \times 10^{10}$ & 50.0 & $1.5 \times 10^{6}$ \\
\hline Tunnel lining & $2.6 \times 10^{4}$ & 0.20 & $3.25 \times 10^{10}$ & - & - \\
\hline Cushion & $2.4 \times 10^{4}$ & 0.20 & $2.25 \times 10^{10}$ & - & - \\
\hline Shock absorption layer & $1 \times 10^{4}$ & 0.45 & $3 \times 10^{10}$ & 0.5 & $5 \times 10^{6}$ \\
\hline Silty clay & $1.94 \times 10^{4}$ & 0.36 & $1.71 \times 10^{10}$ & 21.0 & $4.4 \times 10^{4}$ \\
\hline
\end{tabular}

TABLE 2: Calculation conditions.

\begin{tabular}{lcc}
\hline Condition & Calculation content & Thickness of shock absorption layer \\
\hline 1 & No shock absorption layer & - \\
2 & With shock absorption layer & $50 \mathrm{~mm}$ \\
3 & With shock absorption layer & $100 \mathrm{~mm}$ \\
4 & With shock absorption layer & $150 \mathrm{~mm}$ \\
\hline
\end{tabular}

\section{Numerical Simulation Results and Antiseismic Effect Analysis}

4.1. Maximum Convergence Value of Side Wall. The maximum convergence value of the side wall of the tunnel lining under each condition is extracted, and the decreased amplitude of the maximum convergence value of the side wall after setting the shock absorption layer (condition 2 condition 4) is calculated (compared with condition 1). The calculation results are shown in Table 3.

It can be seen from Table 3 that compared with no shock absorption layer, the maximum convergence value of the side wall decreases after the shock absorption layer is set in the tunnel. The maximum convergence value of the side wall of

\begin{tabular}{|c|c|c|c|c|}
\hline S1 & S2 & S3 & S4 & S5 \\
\hline$T$ & $T$ & $T$ & $T$ & $T$ \\
\hline 1 & I & 1 & 1 & I \\
\hline I & 1 & 1 & 1 & i \\
\hline 1 & 1 & 1 & 1 & 1 \\
\hline
\end{tabular}

FIGURE 3: Section distribution.

condition 1 is $1.44 \mathrm{~mm}$ and that of condition 2 is $1.20 \mathrm{~mm}$, which is $14.90 \%$ less than that of condition 1 . The maximum convergence value of the side wall of condition $3 \sim 4$ is also less than that of condition 1 , but the reduction is not as large as that 


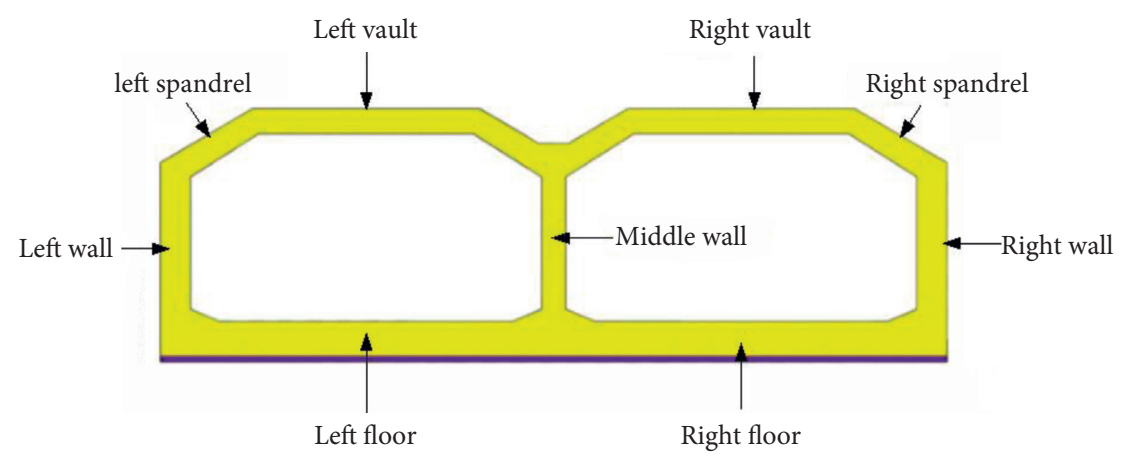

FIgURE 4: Arrangement of measuring points.

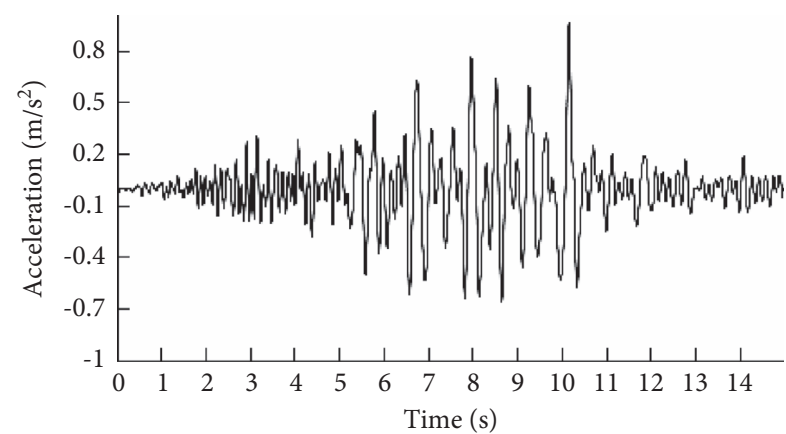

(a)

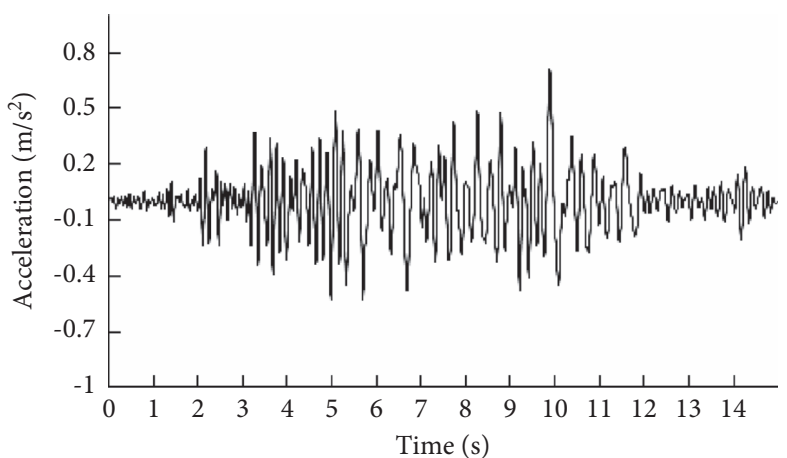

(b)

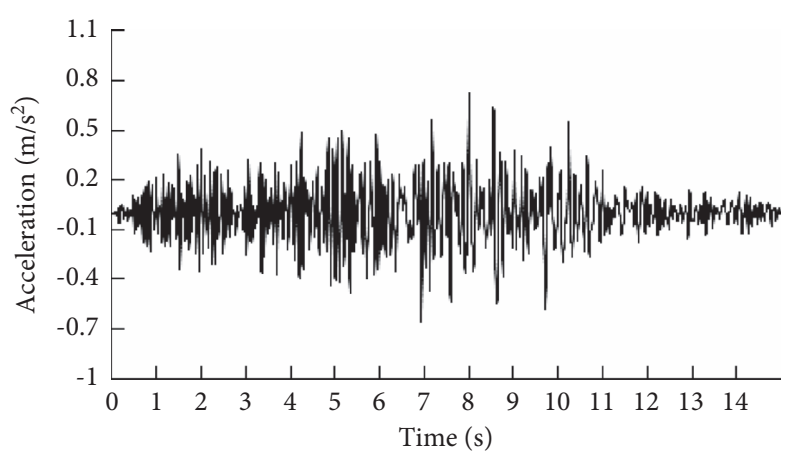

(c)

Figure 5: Acceleration curve. (a) $x$ direction, (b) $y$ direction, and (c) $z$ direction.

of condition 2; among them, the reduction of condition 4 is the smallest. With the increase of the thickness of the shock absorption layer, the decrease of the maximum convergence value of the side wall continues to decrease. This phenomenon is due to the influence of the lateral dislocation between the tunnel lining and the surrounding rock. The influence of lateral dislocation will increase with the increase of the thickness of the shock absorption layer. According to the convergence analysis of the side wall, the effect of a $50 \mathrm{~mm}$ thick shock absorption layer is the best.

4.2. Principal Stress. According to the simulation results, the maximum and minimum principal stress cloud charts of tunnel lining under various conditions are obtained, as shown in Figures 6 and 7. At the same time, the maximum and minimum principal stresses of the tunnel lining under various conditions (the principal stress is positive in tension and negative in compression) are extracted, and the effect of different thickness shock absorption layers (condition $2 \sim$ condition 4) on the maximum and minimum principal stresses is calculated (compared with condition 1). The calculation results are shown in Table 4 .

It can be seen from Figures 6, 7, and Table 4 that compared with no shock absorption layer, the maximum and minimum principal stress of each condition decreases after setting the shock absorption layer. In condition 1 , the maximum value of maximum and minimum principal stresses is $3.231 \times 10^{6} \mathrm{~Pa}$ and $-5.816 \times 10^{6} \mathrm{~Pa}$, respectively. After setting the shock absorption layer, in terms of maximum principal stress, the maximum value of the maximum principal stress of condition 2 is larger than the 
TABLE 3: Maximum convergence value of side wall.

\begin{tabular}{lcc}
\hline Condition & Maximum convergence value of side wall $(\mathrm{mm})$ & Antiseismic effect $(\%)$ \\
\hline 1 & 1.41 & - \\
2 & 1.20 & 14.90 \\
3 & 1.32 & 6.63 \\
4 & 1.35 & 4.65 \\
\hline
\end{tabular}
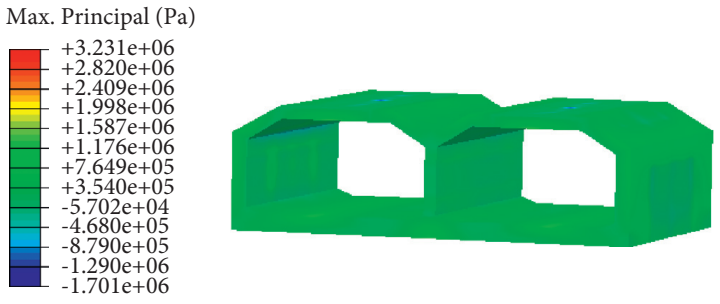

(a)
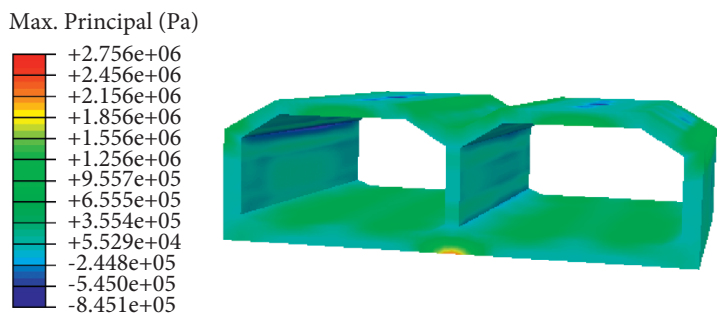

Max. Principal $(\mathrm{Pa})$ $+2.780 \mathrm{e}+06$ $+2.471 \mathrm{e}+06$

(c) $+2.161 \mathrm{e}+06$ $+1.543 \mathrm{e}+06$ $+1.233 \mathrm{e}+06$ $+9.240 \mathrm{e}+05$
$+6.146 \mathrm{e}+05$ $+6.146 \mathrm{e}+05$
$+3.052 \mathrm{e}+05$ $-4.112 \mathrm{e}+03$ $3.135 \mathrm{e}+05$ $-6.228 \mathrm{e}+05$ $-9.322 \mathrm{e}+05$

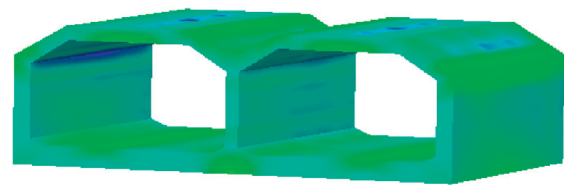

(b)

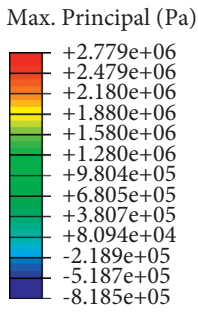

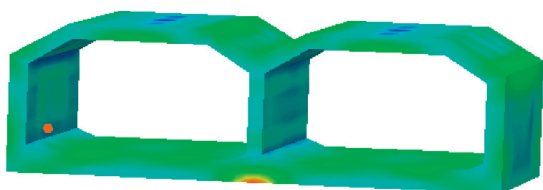

(d)

FIgure 6: Cloud chart of maximum principal stress of tunnel lining. (a) Condition 1; (b) Condition 2; (c) Condition 3; (d) Condition 4.

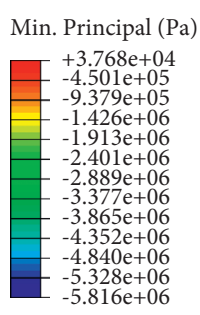

Min. Principal (Pa)

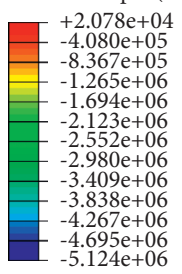

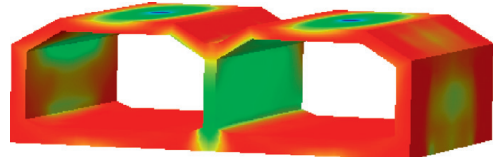

(a)

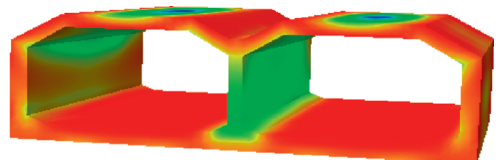

(c)

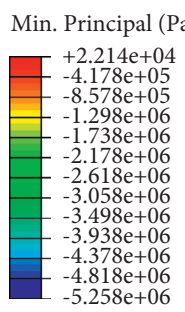

$-5.258 \mathrm{e}+06$

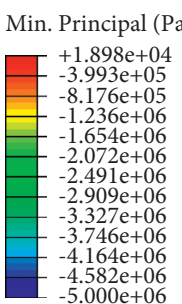

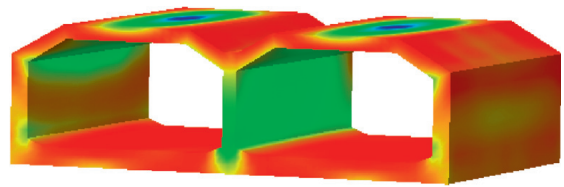

(b)

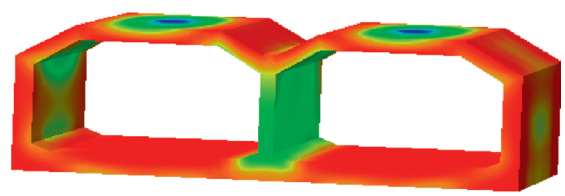

(d)

Figure 7: Cloud chart of minimum principal stress of tunnel lining. (a) Condition 1; (b) Condition 2; (c) Condition 3; (d) Condition 4.

other conditions, which is $2.780 \times 10^{6} \mathrm{~Pa}$ and $13.96 \%$ lower than that of condition 1 ; the maximum value of the maximum principal stress of condition 3 is smaller than the other conditions, which is $2.756 \times 10^{6} \mathrm{~Pa}$ and $14.70 \%$ lower than that of condition 1 . In terms of minimum principal stress, the maximum value of the minimum principal stress of condition 2 is larger than the other conditions, which is $-5.258 \times 10^{6} \mathrm{~Pa}$ and $9.59 \%$ lower than that of condition 1 ; the maximum value of the maximum principal stress of condition 4 is smaller than the other conditions, which is $-5.000 \times 10^{6} \mathrm{~Pa}$ and $14.03 \%$ lower than that of condition 1 . From the analysis of the maximum and minimum principal stress, it can be seen that the principal stress of condition 3 and condition 4 decreases greatly, so it is better to set the rubber plate with the thickness of $100 \mathrm{~mm}$ or $150 \mathrm{~mm}$. 
TABle 4: Principal stress and antiseismic effect.

\begin{tabular}{lcccc}
\hline \multirow{2}{*}{ Condition } & \multicolumn{2}{c}{ Maximum principal stress } & \multicolumn{2}{c}{ Minimum principal stress } \\
& Maximum value $(\mathrm{Pa})$ & Antiseismic effect $(\%)$ & Maximum value $(\mathrm{Pa})$ & Antiseismic effect $(\%)$ \\
\hline 1 & $3.231 \times 10^{6}$ & - & $-5.816 \times 10^{6}$ & - \\
2 & $2.780 \times 10^{6}$ & 13.96 & $-5.258 \times 10^{6}$ & 9.59 \\
3 & $2.756 \times 10^{6}$ & 14.70 & $-5.124 \times 10^{6}$ & 11.90 \\
4 & $2.779 \times 10^{6}$ & 13.99 & $-5.000 \times 10^{6}$ & 14.03 \\
\hline
\end{tabular}

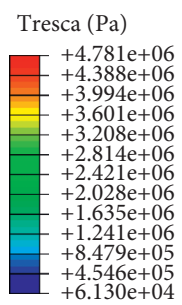

Tresca $(\mathrm{Pa})$

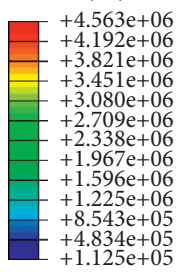

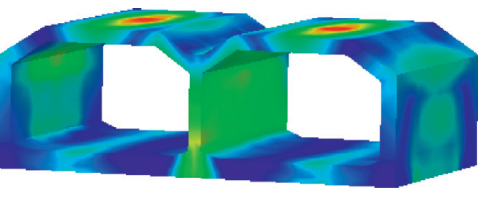

(a)

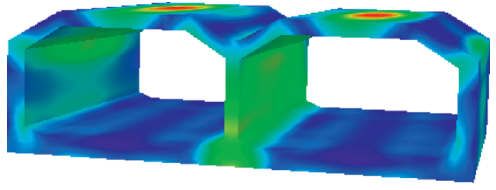

(c)

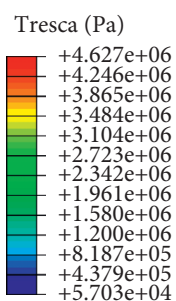

$5.703 \mathrm{e}+04$

Tresca $(\mathrm{Pa})$

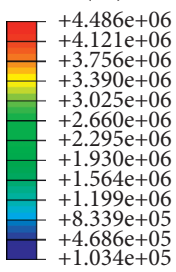

$+4.686 \mathrm{e}+05$
$+1.034 \mathrm{e}+05$

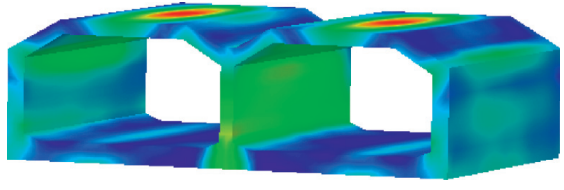

(b)

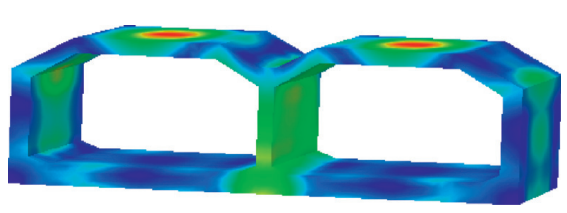

(d)

FIgURE 8: Cloud chart of maximum shear stress of tunnel lining: (a) Condition 1; (b) Condition 2; (c) Condition 3; (d) Condition 4.

4.3. Maximum Shear Stress. According to the simulation results, the maximum shear stress cloud chart of tunnel lining under various conditions is obtained, as shown in Figure 8. At the same time, the maximum shear stress of the tunnel lining under various conditions is extracted, and the effect of different thickness shock absorption layers (condition $2 \sim$ condition 4 ) on the maximum shear stress is calculated (compared with condition 1). The calculation results are shown in Table 5.

It can be seen from Figure 8 and Table 5 that the maximum shear stress of each condition occurs in the middle part of the tunnel. Compared with no shock absorption layer, the maximum shear stress decreases after the shock absorption layer is set. The maximum shear stress of condition 1 is the largest, which is $4.781 \times 10^{6} \mathrm{~Pa}$. The maximum shear stress of condition 4 is the smallest, which is $4.486 \times 10^{6} \mathrm{~Pa}$, which is $6.17 \%$ less than that of condition 1 , and the antiseismic effect is the most obvious. The maximum shear stress of condition 2 is $4.627 \times 10^{6} \mathrm{~Pa}$, and the decrease is the smallest, which is reduced by $3.22 \%$. The maximum shear stress analysis shows that the thicker the shock absorption layer is, the better the antiseismic effect is.

4.4. Safety Factor. The minimum safety factor of each monitoring section under each condition is shown in Figure 9. The effect of setting different thickness shock absorption layers (condition $2 \sim$ condition 4 ) on the minimum safety factor of tunnel lining is calculated (compared with condition 1), and the results are shown in Table 6.
TABle 5: Maximum shear stress and antiseismic effect.

\begin{tabular}{lcc}
\hline Condition & Maximum shear stress $(\mathrm{Pa})$ & Antiseismic effect (\%) \\
\hline 1 & $4.781 \times 10^{6}$ & - \\
2 & $4.627 \times 10^{6}$ & 3.22 \\
3 & $4.563 \times 10^{6}$ & 4.56 \\
4 & $4.486 \times 10^{6}$ & 6.17 \\
\hline
\end{tabular}

As can be seen from Figure 9 and Table 6, compared with the safety factor of each section of the tunnel without the shock absorption layer, the safety factor of each section of the tunnel is greatly improved after setting different thicknesses of the shock absorption layer, and the increase of the safety factor in condition 3 and condition 4 is basically the same, which is larger than that in condition 2 . The minimum safety factor of the four conditions is all located at S3. The minimum safety factor of the tunnel in condition 1 is 2.74 , and the minimum safety factor of the tunnel in condition 2 is 3.45 , which is $25.91 \%$ higher than that in condition 1 . The section with the largest increase in condition 2 is $\mathrm{S} 4$, which is $32.13 \%$ higher than that in condition 1 . The minimum safety factor of the tunnel in condition 3 is 4.12 , which is $50.36 \%$ higher than that in condition 1 . The section with the largest increase in condition 3 is S2, which is $54.45 \%$ higher than that in condition 1 . The minimum safety factor of the tunnel in condition 4 is 4.19 , which is $52.92 \%$ higher than that in condition 1 . The section with the largest increase in condition 4 is S4, which is $53.07 \%$ higher than that in condition 1 . 


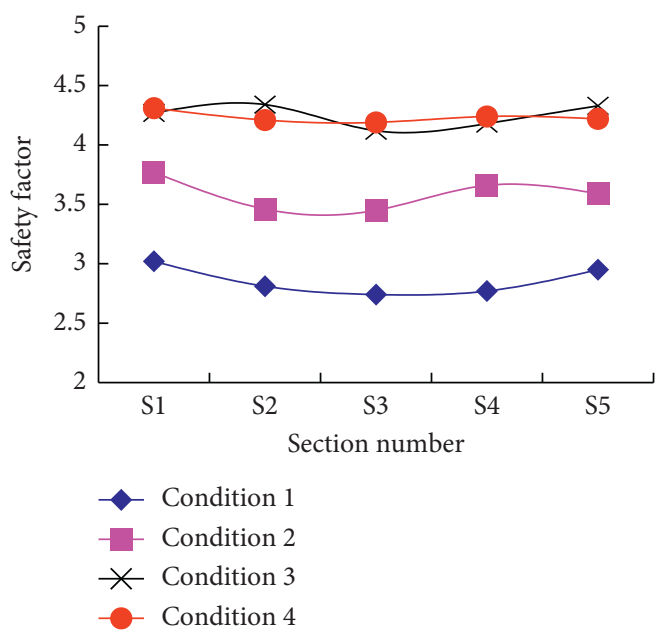

FIGURE 9: Minimum safety factor.

Table 6: Minimum safety factor and antiseismic effect.

\begin{tabular}{|c|c|c|c|c|c|c|c|}
\hline \multirow[b]{2}{*}{ Section number } & \multirow{2}{*}{$\begin{array}{l}\text { Condition } 1 \\
\text { Safety factor }\end{array}$} & \multicolumn{2}{|c|}{ Condition 2} & \multicolumn{2}{|c|}{ Condition 3} & \multicolumn{2}{|c|}{ Condition 4} \\
\hline & & Safety factor & Antiseismic effect (\%) & Safety factor & Antiseismic effect (\%) & Safety factor & $\begin{array}{l}\text { Antiseismic } \\
\text { effect }(\%)\end{array}$ \\
\hline S1 & 3.02 & 3.77 & $24.83 \%(\uparrow)$ & 4.27 & $41.39 \%(\uparrow)$ & 4.31 & $42.72 \%(\uparrow)$ \\
\hline S2 & 2.81 & 3.46 & $23.13 \%(\uparrow)$ & 4.34 & $54.45 \%(\uparrow)$ & 4.21 & $49.82 \%(\uparrow)$ \\
\hline S3 & 2.74 & 3.45 & $25.91 \%(\uparrow)$ & 4.12 & $50.36 \%(\uparrow)$ & 4.19 & $52.92 \%(\uparrow)$ \\
\hline S4 & 2.77 & 3.66 & $32.13 \%(\uparrow)$ & 4.18 & $50.90 \%(\uparrow)$ & 4.24 & $53.07 \%(\uparrow)$ \\
\hline S5 & 2.95 & 3.59 & $21.69 \%(\uparrow)$ & 4.33 & $46.78 \%(\uparrow)$ & 4.22 & $43.05 \%(\uparrow)$ \\
\hline
\end{tabular}

When the thickness of the shock absorption layer increases from $50 \mathrm{~mm}$ to $100 \mathrm{~mm}$, the safety factor of each section of the tunnel also increases. When the thickness of the shock absorption layer increases from $100 \mathrm{~mm}$ to $150 \mathrm{~mm}$, the safety factor of each section of the tunnel does not increase significantly. Therefore, considering the safety and cost, the effect of setting a $100 \mathrm{~mm}$ thick shock absorption layer is the best.

\section{Conclusions}

(1) According to the analysis of the side wall convergence, the side wall convergence of the tunnel lining is reduced after setting different thicknesses of the shock absorption layer. When a $50 \mathrm{~mm}$ thick shock absorption layer is set, the reduction of the maximum convergence of the tunnel side wall is the biggest, which is $14.90 \%$. When the thickness of the $150 \mathrm{~mm}$ shock absorption layer is set, the reduction of the maximum convergence of the tunnel side wall is the smallest, which is $4.65 \%$. The reason for this phenomenon is that the tunnel lining and surrounding rock have lateral dislocation. The thicker the shock absorption layer is, the greater the influence of lateral dislocation is.

(2) From the analysis of principal stress, it can be seen that the principal stress decreases after the construction of shock absorption layer. When the shock absorption layer is $50 \mathrm{~mm}$ thick, the reduction of the maximum and minimum principal stresses is the smallest in the three conditions. In terms of the maximum principal stress, the maximum reduction is $14.70 \%$ when the shock absorption layer is $100 \mathrm{~mm}$ thick. In terms of the minimum principal stress, the maximum reduction is $14.03 \%$ when the $150 \mathrm{~mm}$ thick shock absorption layer is set. The results show that the antiseismic effect is better when the thickness of the shock absorption layer is $100 \mathrm{~mm}$ or $150 \mathrm{~mm}$.

(3) From the analysis of the maximum shear stress, it can be seen that the maximum shear stress is reduced after the construction of the shock absorption layer. The maximum shear stress is reduced by $6.17 \%$ after setting a $150 \mathrm{~mm}$ thick shock absorption layer, which is the largest of the three conditions. The decrease of the maximum shear stress is small when the shock absorption layer is $50 \mathrm{~mm}$ and $100 \mathrm{~mm}$.

(4) The safety factor of each section of the tunnel increases after the construction of the shock absorption layer, and the increase is the smallest when the shock absorption layer is $50 \mathrm{~mm}$ thick. The minimum safety factor of the tunnel with a a100 mm thick shock absorption layer is 4.12 , which is increased by $50.36 \%$; the section with the biggest increase in the safety factor of the tunnel is S2, and the biggest increase is $54.45 \%$. The minimum safety factor of the tunnel with a150 mm thick shock absorption layer is 4.19 , increased by $52.92 \%$; the section with the largest 
increase in the safety factor of the tunnel is S4, and the largest increase is $53.07 \%$. The effect of a $100 \mathrm{~mm}$ and $150 \mathrm{~mm}$ shock absorption layers is basically the same.

(5) When the shock absorption layer is set in the tunnel, the displacement and principal stress are controlled, and the safety factor is increased. When the shock absorption layer is $100 \mathrm{~mm}$ or $150 \mathrm{~mm}$ thick, the maximum and minimum principal stress and the maximum shear stress are significantly reduced, and the reduction range is basically the same; the safety factor also has a similar increase range. Therefore, the two thickness shock absorption layers can meet the seismic requirements of the tunnel. On this basis, considering the construction cost, a $100 \mathrm{~mm}$ thick shock absorption layer is selected. In conclusion, the effect of a $100 \mathrm{~mm}$ thick shock absorption layer is better than that of $50 \mathrm{~mm}$ and $150 \mathrm{~mm}$.

\section{Data Availability}

The data used to support the findings of this study are available within the article.

\section{Conflicts of Interest}

The authors declare that there are no conflicts of interest regarding the publication of this paper.

\section{References}

[1] T. Asakura, Y. Shiba, S. Matsuoka, T. Oya, and K. Yashiro, "Damage to mountain tunnels by earthquake and its mechanism," Doboku Gakkai Ronbunshu, vol. 2000, no. 659, pp. 27-38, 2000.

[2] Y. Kazuhide, K. Yoshiyuki, and S. Mitsuru, "Historical earthquake damage to tunnels in Japan and case studies of railway tunnels in the 2004 niigataken-chuetsu earthquake," Quarterly Report of RTRI, vol. 48, pp. 136-141, 2007.

[3] M. Ghadimi, K. Shahriar, and H. Jalalifar, "A new analytical solution for the displacement of fully grouted rock bolt in rock joints and experimental and numerical verifications," Tunnelling and Underground Space Technology, vol. 50, pp. 143151, 2015.

[4] L. Cui, J. J. Zheng, Q. Sheng, and Y. Pan, "A simplified procedure for the interaction between fully-grouted bolts and rock mass for circular tunnels," Computers and Geotechnics, vol. 106, pp. 177-192, 2019.

[5] Q. Wang, Q. Qin, B. Jiang, H. C. Yu, R. Pan, and S. C. Li, "Study and engineering application on the bolt-grouting reinforcement effect in underground engineering with fractured surrounding rock," Tunnelling and Underground Space Technology, vol. 84, pp. 237-247, 2019.

[6] Y. Wu, Y. Hao, J. Tao, Y. Teng, and X. Dong, "Non-destructive testing on anchorage quality of hollow grouted rock bolt for application in tunneling, lessons learned from their uses in coal mines," Tunnelling and Underground Space Technology, vol. 93, p. 103094, 2019.

[7] H. Zhou, M. Xiao, and J. Chen, "Analysis of a numerical simulation method of fully grouted and anti-seismic support bolts in underground geotechnical engineering," Computers and Geotechnics, vol. 76, pp. 61-74, 2016.
[8] S. R. R. T. Prathipati, I. Khan, C. B. K. Rao, and H. Kasagani, "A study on the fiber distribution characteristics of hybrid fiber reinforced high strength concrete with steel and glass fibers," Materials Today: Proceedings, vol. 43, 2020.

[9] S. K. Woo, K. J. Kim, and S. H. Han, "Tensile cracking constitutive model of steel fiber reinforced concrete (SFRC)," KSCE Journal of Civil Engineering, vol. 18, no. 5, pp. 14461454, 2014.

[10] C. L. Xin, Z. Z. Wang, J. M. Zhou, and B. Gao, "Shaking table tests on seismic behavior of polypropylene fiber reinforced concrete tunnel lining," Tunnelling and Underground Space Technology, vol. 88, pp. 1-15, 2019.

[11] M. Jamshidi Avanaki, A. Hoseini, S. Vahdani, C. De Santos, and A. de la Fuente, "Seismic fragility curves for vulnerability assessment of steel fiber reinforced concrete segmental tunnel linings," Tunnelling and Underground Space Technology, vol. 78, pp. 259-274, 2018.

[12] M. Jamshidi Avanaki, A. Hoseini, S. Vahdani, and A. de la Fuente, "Numerical-aided design of fiber reinforced concrete tunnel segment joints subjected to seismic loads," Construction and Building Materials, vol. 170, pp. 40-54, 2018.

[13] C. L. Xin, Z. Z. Wang, and J. Yu, "The evaluation on shock absorption performance of buffer layer around the cross section of tunnel lining," Soil Dynamics and Earthquake Engineering, vol. 131, Article ID 106032, 2020.

[14] C. X. Huang, X. Wang, H. Zhou, and Y. Liang, "Damping effects of different shock absorbing materials for tunnel under seismic loadings," Journal of Vibroengineering, vol. 21, no. 5, 2019.

[15] Q. Jiang and J. Zhang, "Anti-seismic capability and property optimization of foam concrete in tunnel as isolation layer," Advanced Science Letters, vol. 4, pp. 691-695, 2011.

[16] L. Su, H. Liu, G. Yao, and J. Zhang, "Experimental study on the closed-cell aluminum foam shock absorption layer of a high-speed railway tunnel," Soil Dynamics and Earthquake Engineering, vol. 119, pp. 331-345, 2019.

[17] G. Y. Cui, X. G. Wu, M. N. Wang, D. Y. Wang, and C. A. Zhu, "Model tests on damping of shock absorption layer of stickslip fracture tunnel in highly seismic areas," Chinese Journal of Geotechnical Engineering, vol. 39, pp. 2125-2131, 2017.

[18] C. L. Xin, B. Gao, J. M. Zhou, Y. S. Shen, and X. J. Quan, "Shaking table tests on performances of anti-seismic and damping measures for fault-crossing tunnel structures," Yantu Gongcheng Xuebao/Chinese Journal of Geotechnical Engineering, vol. 36, pp. 1414-1422, 2014.

[19] S. S. Wang and B. Gao, "Damping mechanism and shaking table test on mountain tunnel linings with buffer layers," Chinese Journal of Rock Mechanics and Engineering, vol. 35, pp. 592-603, 2016.

[20] Ministry of Transport of the People's Republic of China, Code for Design of Road TunnelChina Communications Press, Beijing, China, 2004.

[21] Compiling Committee of Seismic Intensity Zoning Map of China, "Seismic Intensity Zoning Map of China (1990) and its explanation," Earthquake Research in China, vol. 8, pp. 415426, 1994.

[22] Ministry of Housing and Urban-Rural Development of the People's Republic of China, Code for Design of Concrete Structures, China Architecture \& Building Press, Beijing, China, GB 50010-2010, 2010.

[23] Ministry of Transport of the People's Republic of China, Specifications for Design of Highway Tunnels Section 1 Civil Engineering, China Communications Press, Beijing, China, 2018. 